\title{
Original
}

\section{Determination of Cation Distribution in}

\author{
$\mathrm{ZnFe}_{2} \mathrm{O}_{4}, \mathrm{NiFe}_{2} \mathrm{O}_{4}$ and $\mathrm{NiAl}_{2} \mathrm{O}_{4}$ Spinels by
}

An In-house Anomalous X-ray Scattering Method

\author{
by

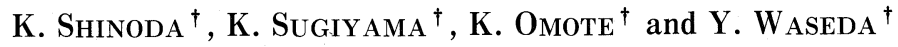

\begin{abstract}
An in-house anomalous X-ray scatterig (AXS) method has been done for determining cation distribution in $\mathrm{ZnFe}_{2} \mathrm{O}_{4}, \mathrm{NiFe}_{2} \mathrm{O}_{4}$ and $\mathrm{NiAl}_{2} \mathrm{O}_{4}$ spinels using the anomalous dispersion effect near the $K$ absorption edges of $\mathrm{Zn}$ and $\mathrm{Ni}$. When introduced the ratio $(x)$ of the number of divalent cations of $M$ element, $M_{A}$, residing in the tetrahedral A-site to the total number of $M$ element, $x=M_{A}$ $M_{\text {total }}$, the measured intensity ratios of three reflection peaks with two energies close to the $K$ edge of $\mathrm{Zn}$ or Ni can be quantitatively explained only by assigning the case where $\mathrm{ZnFe}_{2} \mathrm{O}_{4}$ is the normal type $(x=1.0)$ and $\mathrm{NiFe}_{2} \mathrm{O}_{4}$ is the inverse type $(x=0.0)$ spinel structure. On the other hand, the results for $\mathrm{NiAl}_{2} \mathrm{O}_{4}$ suggests that $15 \%$ of $\mathrm{Ni}^{2+}$ cations occupy the tetrahedral $\mathrm{A}$-site $(x=0.15)$ and the rest are octahedrally coordinated. The usefulness of the in-house AXS method is rather surprisingly well-recognized, particularly for obtaining the cation distribution in crystalline materials containing two elements of nearly the same atomic number.
\end{abstract}

Key Words : Anomalous X-ray Scattering, In-house Facility, Cation Distribution

\section{I . Introduction}

The physical and chemical properties of materials have close relation to their atomic scale structures. In the spinels, there are 32 octahedral and 64 tetrahedral interstices formed by oxygens available for cations in a unit cell and half of the octahedral and one-eighth of the tetrahedral sites are known to be occupied. For example, $\mathrm{Zn}^{2+}$ ion usually prefers the tetrahedral sites in $\mathrm{ZnFe}_{2} \mathrm{O}_{4}$ and is of the normal type ${ }^{12)}$. On the other hand, $\mathrm{NiFe}_{2} \mathrm{O}_{4}$ is classified as inverse spinel, where the tetrahedral

\footnotetext{
Received October 9, 1995

Institute for Advanced Materials Processing (SOZAIKEN)

† Tohoku University, Aoba-ku Sendai 980-77, Japan.
} 
sites contain only $\mathrm{Fe}^{3+}$ and the residual $\mathrm{Fe}^{3+}$ and all $\mathrm{Ni}^{2+}$ ions are octahedrally coordinated. It is of great importance to determine the degree of inversion, because the magnetic properties of these ferrite spinels depend heavily upon the cation distribution.

For obtaining the atomic scale structures of materials, X-ray powder diffraction is widely used and it is a well estabilished useful method for both qualitative and quantitative analysis. However, there are generally insufficient differences in the X-ray diffraction intensities of two elements of nearly the same atomic number to be identified. This is certainly the case for ferrite spinels such as $\mathrm{ZnFe}_{2} \mathrm{O}_{4}$ and $\mathrm{NiFe}_{2} \mathrm{O}_{4}$, because the $\mathrm{X}$-ray scattering abilities of these components are not welldiscriminated, so that the determination of cation distribution is difficult. The use of the anomalous $\mathrm{X}$-ray scattering (hereafter referred to as AXS) at the energies near the absorption edge of a specific element is one way to overcome this difficulty by obtaining an appreciable difference in the crystallographic structure factors under these conditions. The advantage of the AXS method to structural analysis of crystalline materials has long been suggested since a synchrotron radiation X-ray source recently became popular for studies of materials. However, the results of this AXS method are still limited to a small number of compositions, because of the limitation of beam time in a synchrotron facility. Thus, it is strongly required to establish an in-house AXS method for crystalline materials by well-confirming its usefullness.

The main purpose of this paper is to present the AXS results using an in-house AXS facility for determining the cation distribution in $\mathrm{ZnFe}_{2} \mathrm{O}_{4}, \mathrm{NiFe}_{2} \mathrm{O}_{4}$ and $\mathrm{NiAl}_{2} \mathrm{O}_{4}$, which are classified into the compounds with spinel structure.

\section{Principle of the AXS method for structural analysis of spinels}

The X-ray scattering amplitude $f$ is known to consist of a photon energy independent term $f^{0}$ and the energy dependent real $f$ ' and imaginary $f$ " terms, referred to as anomalous scattering factors and it can be given as follows ${ }^{3)}$.

$$
\boldsymbol{f}(\boldsymbol{Q}, \boldsymbol{E})=\boldsymbol{f}^{0}(\boldsymbol{Q})+\boldsymbol{f}^{\prime}(\boldsymbol{E})+\boldsymbol{i} \boldsymbol{f}^{\prime \prime}(\boldsymbol{E})
$$

where $Q$ and $E$ are the wave vector and the energy of the incident X-rays, respectively. The variations of energy dependent terms $f^{\prime}(E)$ and $f^{\prime \prime}(E)$ are usually small. However, when the energy of the incident X-rays is not far from an absorption edge of one of the constituents, the change in $f$ ' and $f$ " terms can no longer be considered as insignificant. Their variation for the energy is given in the bottom part of Fig. 1 using the K-absorption edge of $\mathrm{Zn}$ as an example. These energy dependence of X-ray scattering amplitude provides important probes for the study of fine structure or electronic states of various materials.

The intensity profile of the incident $\mathrm{X}$-ray produced from a tungsten target vs energy are shown in Fig. 1 together with the anomalous scattering factors $f^{\prime}$ and $f^{\prime \prime}$ for $\mathbf{Z n}^{4)}$ calculated using CromerLiberman's relativistic scheme for an isolate atom ${ }^{5)}$. The incident energies employed in the present AXS measurements are also indicated with vertical broken lines in this figure. It may be worth mentioning that the agreement between the experimental and theoretical values of the anomalous scattering factors is well confirmed at the lower energy side of the absorption edge. In addition, in this lower energy side of the absorption edge, the detected energy dependence in AXS variation of $f$ " is very small 


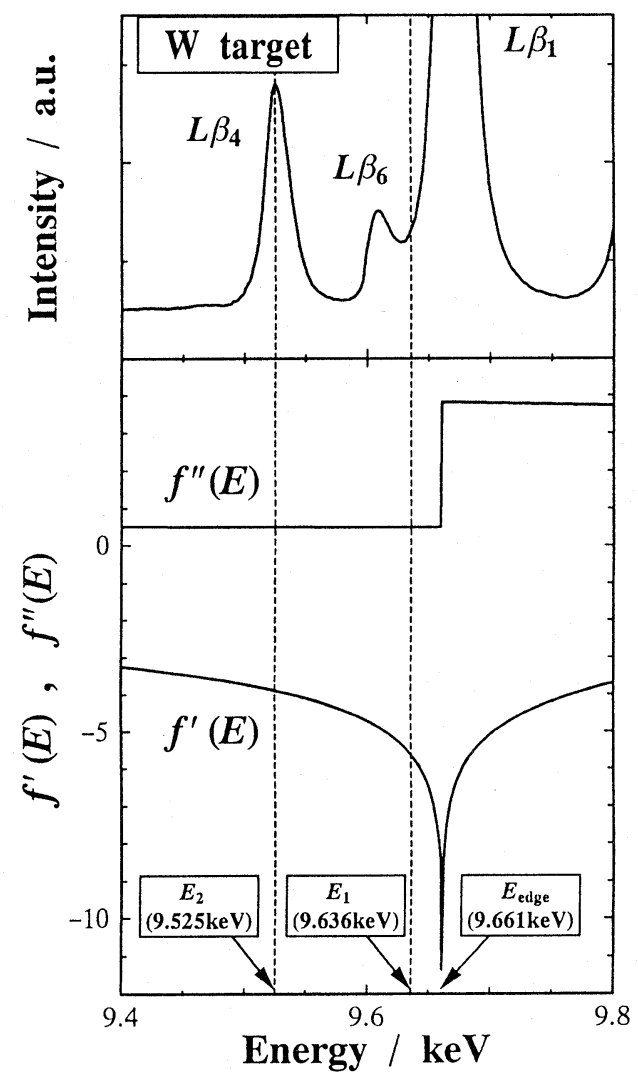

Fig. 1 The energy dependence of anomalous dispersion terms $f$ and $f$ " near $\mathrm{Zn} K$ absorption edge (bottom) and the incident X-ray intensity profile produced from a tungsten target in the operation of $9 \mathrm{~kW}$ (top).

and almost constant under this condition. These are the reasons for selecting these incident energies in this work.

The diffracted intensity of the $h k l$ reflection from a crystalline powder at an energy of $E$ in reflection geometry may be given in the following form ${ }^{6}$,

$$
I_{h k l}=k p I_{0}(E) \lambda^{3} P L A \frac{\left|F_{h k l}(E)\right|^{2}}{\nu_{c^{2}}}
$$

where the symbols have their usual crystallographic meanings as follows.
$I_{h k l}:$ integrated intensity
$L$ : Lorentz factor
$\lambda$ : wavelength
$A$ : absorption factor
$I_{0}:$ incident intensity
$\nu_{\mathrm{c}}:$ volume of unit cell
$p:$ multiplicity factor
$k:$ scale factor
$P$ : polarization 
The crystallographic structure factor $F_{h k l}$ is known to be given by the expression ${ }^{6)}$ ),

$$
F_{h k l}=\sum_{j} f_{j} \exp \left[B_{j}(\sin \theta / \lambda)^{2}\right] \exp \left[2 \pi i\left(h x_{j}+k y_{j}+l z_{j}\right)\right]
$$

where $\left(x_{j}, y_{i}, z_{j}\right)$ and $B_{j}$ are the fractional coordinates and the isotropic temperature factor, respectively, for the $j$-th component. The summation extends over all the atoms in the unit cell.

In spinel structure expressed by the general formula of $\mathrm{MN}_{2} \mathrm{O}_{4}$ where $\mathrm{M}$ is a divalent cation such as $\mathrm{Zn}^{2+}$ and $\mathrm{Ni}^{2+}$, and $\mathrm{N}$ is a trivalent cation such as $\mathrm{Fe}^{3+}$ and $\mathrm{Al}^{3+}$, eq. (3) can be rewritten by the following three terms which correspond to the contributions from atoms occupying the tetrahedral A-site, the octahedral B-site and oxygens $(\mathrm{O})$.

$$
\begin{aligned}
& F_{h k l}=f_{A} T_{A} S_{A}+f_{B} T_{B} S_{B}+f_{o} T_{o} S_{O} \\
& T_{a}=\exp \left[B_{\alpha}(\sin \theta / \lambda)^{2}\right] \\
& S_{\alpha}=\sum_{j_{\alpha}} \exp \left[2 \pi i\left(h x_{j}+k y_{j}+l z_{j}\right)\right] \quad(\alpha=A, B, O)
\end{aligned}
$$

When we also introduce the ratio ( $x$ ) of the number of divalent cations of $M$ element, $M_{A}$, occupying the tetrahedral A-site to the total number, $\boldsymbol{x}=\mathrm{M}_{\mathrm{A}} / \mathrm{M}_{\text {total }}$, the scattering factors $f_{A}$ and $f_{B}$ in eq. (4) are given as a function of $x$, as follows.

$$
\begin{aligned}
& f_{A}=x f_{M}+(1-x) f_{N} \\
& f_{B}=\frac{1-x}{2} f_{M}+\frac{1+x}{2} f_{N}
\end{aligned}
$$

It should be mentioned here that $x=1.0$ and $x=0.0$ correspond to the cation distribution of all $\mathrm{M}^{2+}$ cations occupying the tetrahedral A-site (nomal spinel) and the octahedral B-site (inverse spinel), respectively.

On the other hand, the intensities are measured at two energies of $E_{1}$ and $E_{2}$ in the close vicinity of the absorption edge of $M$, the following simple but useful relation can readily be obtained.

$$
r_{h k l}=\frac{I_{h k l}\left(E_{1}\right) / \lambda_{E 1}^{3} P_{E 1} L_{E 1}}{I_{h k l}\left(E_{2}\right) / \lambda_{E 2}^{3} P_{E 2} L_{E 2}} \frac{I_{0}\left(E_{1}\right)}{I_{0}\left(E_{2}\right)}=\frac{\left|F_{h k l}\left(E_{1}\right)\right|^{2}}{\left|F_{h k l}\left(E_{2}\right)\right|^{2}}
$$

The detected variation of intensity with energy should be attributed to the reflections originating only from the element correspnding to the absorption edge, since the anomalous dispersion effects arising from other components appear to be insignificant in this energy region. Thus, by comparing the measured $r_{h k l e x p}$ at two energies close to the absorption edge with the calculated $r_{h k l c a l}$ with different $x$ values using eqs. (4) and (5), the site occupancy of $\mathrm{M}^{2+}$ cations can be quantitatively determined. In this data processing, the following $R$-factor and the iterative procedure including the Rietveld analysis ${ }^{8.9)}$, as displayed in Fig. 2, are introduced to obtain a significant solution. 


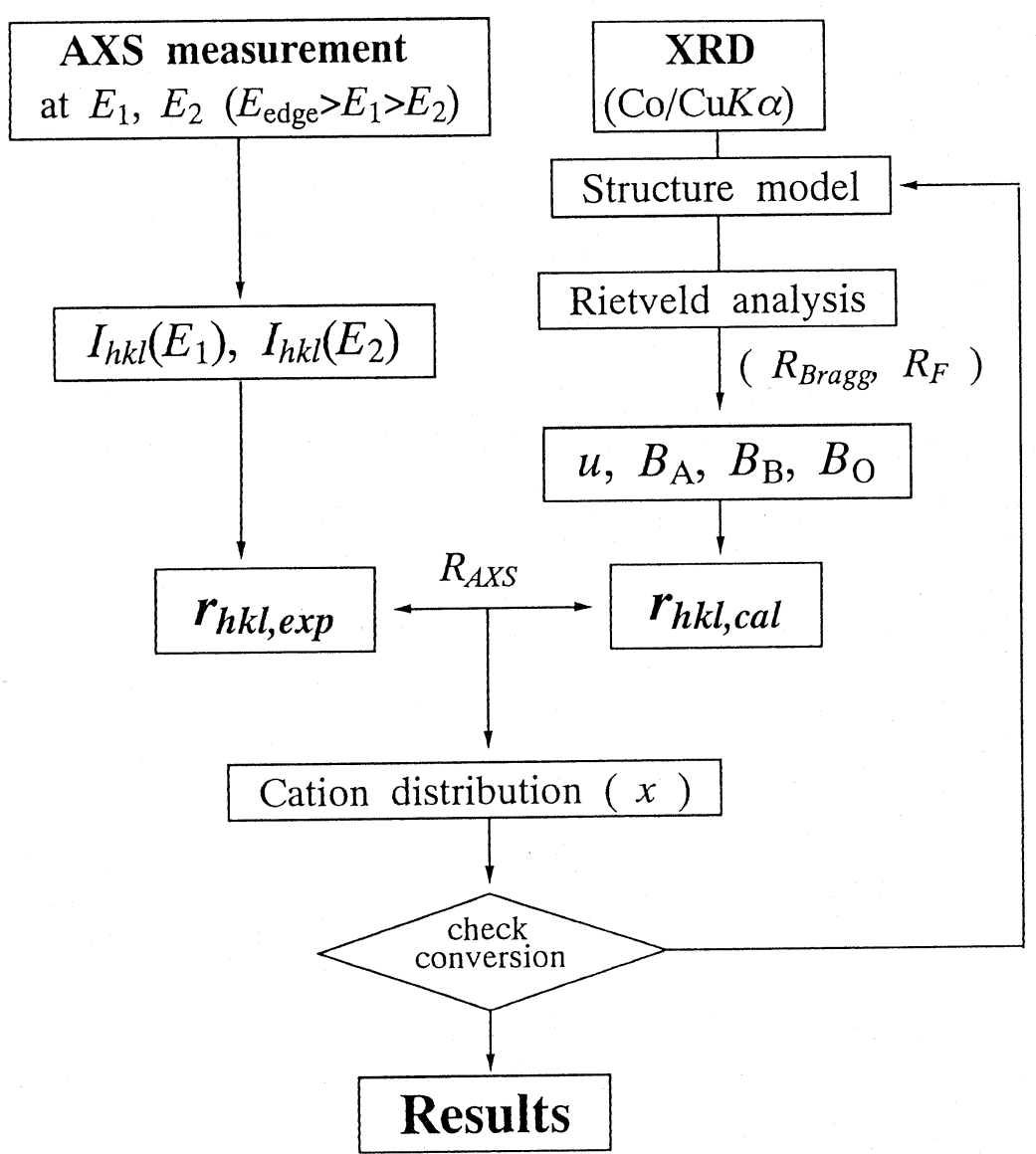

Fig. 2 Flow-chart of the iterative procedure used in the present study for obtaining improved X-ray structural information from the AXS measurement.

Table 1 The value of $S_{\mathrm{A}}, S_{\mathrm{B}}$ and $S_{\mathrm{o}}$ in eq. (4)

\begin{tabular}{c|ccc}
\hline Reflection & $S_{\mathrm{A}}$ & $S_{\mathrm{B}}$ & $S_{\circ}$ \\
\hline 111 & $-4 \sqrt{2}$ & 8 & $8\{\cos 6 \pi u-3 \cos 2 \pi u\}$ \\
220 & -8 & 0 & $16\{\cos 8 \pi u-1\}$ \\
311 & $-4 \sqrt{2}$ & -8 & $8\{\cos 10 \pi u-\cos 2 \pi u+2 \cos 6 \pi u\}$ \\
222 & 0 & 16 & $8\{\cos 12 \pi u+3 \cos 4 \pi u\}$ \\
400 & -8 & 16 & $32\{\cos 8 \pi u\}$ \\
422 & 8 & 0 & $8\{\cos 16 \pi u-2 \cos 8 \pi u+1\}$ \\
440 & 8 & 16 & $16\{\cos 16 \pi u+1\}$ \\
\hline
\end{tabular}




$$
\boldsymbol{R}_{A X S}=\sum_{h k l}\left[r_{h k l, e x p}-r_{h k l, c a l}\right]^{2}
$$

where $r_{h k l e x p}$ and $r_{h k l c a l}$ are the square ratio of the measured structure factor and the calculated one for a model site occupancy, respectively. It is worth mentioning that the ratio of $I_{0}\left(E_{1}\right) / I_{0}\left(E_{2}\right)$ in eq. (6) was set so as to reproduce the calculated ratio of $\boldsymbol{F}_{440}\left(\boldsymbol{E}_{1}\right) / \boldsymbol{F}_{440}\left(\boldsymbol{E}_{2}\right)$ in the present work, because cations in both A and B-sites, as shown in Table 1, contribute to the intensity of 440 reflection with the same weighting factor and then its ratio is independent of the cation distribution in the spinel structure.

\section{In-house AXS Facility}

The AXS measurements were carried out by the in-house AXS facility at the Institute for Advanced Materials Processing, Tohoku University. For convenience, the experimental setup is schematically shown in Fig. 3. A rotating anode type X-ray generator (Rigaku Rotaflex RU-300) operating at $45 \mathrm{kV}$ and $200 \mathrm{~mA}$ with tungsten or gold target was used as the X-ray source. The incident energies used in the present AXS measurements are 9.525 ( $\left.\mathrm{W} L_{4}\right)$ and $9.636 \mathrm{keV}$, which correspond to 136 and $25 \mathrm{eV}$ below the $\mathrm{Zn} K$ absorption edge $(9.661 \mathrm{keV})$. Similarly, we employed the incident energies of 8.182 and 8.307 $\mathrm{keV}$, which correspond to 150 and $25 \mathrm{eV}$ below the Ni $K$ absorption edge (8.332 keV). These energies

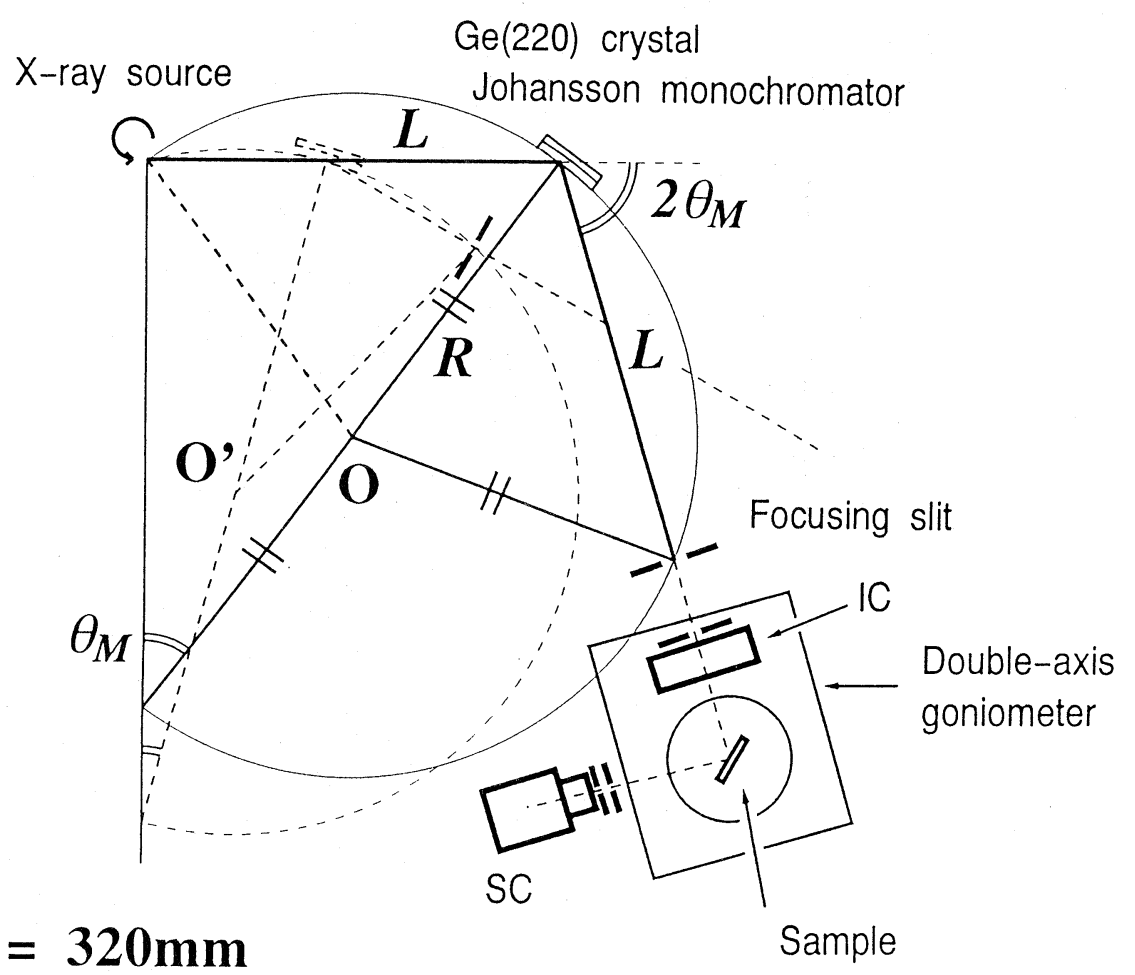

Fig. 3 Schematic diagram of the experimental setup for the present in-house AXS measurements employed in this work. 
were selected by using 220 reflection from a Ge (110) Johansson-cut monochromator $(\mathrm{R}=320 \mathrm{~mm})$. Its optimum energy resolution is about $7 \mathrm{eV}$ at $10 \mathrm{keV}$. It may be suggested that the fluxes of the incident X-ray beam to the sample are of the order of $10^{6}$ photons $/ \mathrm{s}$ at the $\mathrm{Zn} K$ absorption edge in the operation of $9 \mathrm{~kW}$ because of the use of $\mathrm{W} L$ radiation. On the other hand, the fluxes are of the order of $10^{5}$ photons $/ \mathrm{s}$ at the $\mathrm{Ni} K$ absorption edge because of the use of white radiation part only.

The incident $\mathrm{X}$-ray beam intensity is monitored by a $\mathrm{N}_{2}$ gas flow type ion chamber placed in front of the sample. On the other hand, the scattering intensities over the selected range $2 \theta=20$ to $60^{\circ}$ were measured by a scintillation counter. Each measurement of scattering intensity repeated at least 6 times scanning in order to reduce the statistical error.

\section{Results and Discussion}

Samples of $\mathrm{ZnFe}_{2} \mathrm{O}_{4}$ and $\mathrm{NiFe}_{2} \mathrm{O}_{4}$ were prepared from commercial zinc- and nickel-ferrite powder of 99.9 mass\% purity (Kojundo Chemical Laboratory Co., Ltd.) by heating at $773 \mathrm{~K}$ for 60 and 72 hours in air, respectively. A sample of $\mathrm{NiAl}_{2} \mathrm{O}_{4}$ was prepared from reagent powders of $\mathrm{Al}_{2} \mathrm{O}_{3}$ and $\mathrm{NiO}$ of 99.9 mass\% purity from Kanto Chemical Co., Ltd. by mixing and pressing into a pellet and heating at 1173 $\mathrm{K}$ for 48 hours after reacting at $1673 \mathrm{~K}$ for 24 hours for two times in air.

The ordinary X-ray diffraction patterns were also obtained by using $\mathrm{Co} K \alpha$ (for $\mathrm{ZnFe}_{2} \mathrm{O}_{4}$ and $\mathrm{NiFe}_{2} \mathrm{O}_{4}$ ) and $\mathrm{Cu} \mathrm{K} \alpha$ (for $\mathrm{NiAl}_{2} \mathrm{O}_{4}$ ) radiation with a pyrolitic graphite monochromator in a diffracted beam. Data were collected over the range $2 \theta=17$ to $140^{\circ} \quad(\mathrm{Co} K \alpha)$ or 15 to $135^{\circ} \quad(\mathrm{Cu} K \alpha)$. From these ordinary X-ray diffraction data, the crystal structure parameters of the oxygen position $(u)$ and temperature factors of each site $\left(B_{\mathrm{A}}, B_{\mathrm{B}}\right.$ and $\left.B_{0}\right)$ were determined by the Rietveld analysis with a generalized computer package program PFLS ${ }^{9}$. On the other hand, the lattice constants $(a)$ of samples were determined by the whole-powder-pattern decomposition method with a computer program WPP $\mathrm{F}^{10)}$ from the X-ray diffraction patterns with an internal standard of NBS Si $(640 \mathrm{~b})$. Table 2 gives the resultant crystal structure parameters $u$ and $B$ including lattice constant together with the final values of $\boldsymbol{R}_{\text {Bragg }}$ and $\boldsymbol{R}_{\mathrm{F}}{ }^{9)}$ for Rietveld analysis.

The anomalous dispersion effect of divalent cations $\left(\mathrm{Zn}^{2+}\right.$ or $\left.\mathrm{Ni}^{2+}\right)$ on the crystallographic structure factor at two energies can readily be calculated through the $S_{\alpha}$ values in eq. (4) given in Table 1 for given site occupancy in the spinel structure. The calculation includes the crystal structure parameters $u$ and $B$, determined by the Rietveld analysis. As shown in Table 1, the ratios of the crystallographic structure factors for 220 and 422 reflections at two energies are attributed only to cations

Table 2 The values of crystal structure parameters of $a, u$ and $B$ obtained by Rietveld analysis.

\begin{tabular}{l|ccccccc}
\hline & $a[\mathrm{~nm}]$ & $u$ & $B_{\mathrm{A}}\left[\mathrm{nm}^{2}\right]$ & $B_{\mathrm{B}}\left[\mathrm{nm}^{2}\right]$ & $B_{0}\left[\mathrm{~nm}^{2}\right]$ & $R_{\text {Bragg }}[\%]$ & $R_{\mathrm{F}}[\%]$ \\
\hline $\mathrm{ZnFe}_{2} \mathrm{O}_{4}$ & 0.8441 & 0.261 & 0.00609 & 0.00423 & 0.00660 & 2.61 & 2.22 \\
$\mathrm{NiFe}_{2} \mathrm{O}_{4}$ & 0.8339 & 0.255 & 0.00582 & 0.00502 & 0.01041 & 4.98 & 2.59 \\
$\mathrm{NiAl}_{2} \mathrm{O}_{4}$ & 0.8047 & 0.256 & 0.00467 & 0.00434 & 0.00996 & 2.42 & 1.87 \\
\hline
\end{tabular}


occupying the tetrahedral A-site, whereas the ratio for 222 reflection can be allocated to the contribution from cations located in the octahedral B-site.

Fig. 4 shows the energy dependence of the diffraction peak intensities of $\mathrm{ZnFe}_{2} \mathrm{O}_{4}$ and $\mathrm{NiFe}_{2} \mathrm{O}_{4}$ obtained from the AXS measurements with two energies near the absorption edge of $\mathrm{Zn}$ or $\mathrm{Ni}$. In $\mathrm{ZnFe}_{2} \mathrm{O}_{4}$, the energy variation is clearly detected in the 422 reflection peak, but there is no significant energy dependence in the 222 reflection peak. In $\mathrm{NiFe}_{2} \mathrm{O}_{4}$, the reverse behavior is found. The results of $x=\mathrm{M}_{\mathrm{A}} / \mathrm{M}_{\text {total }}$ which give the minimum value of $R_{A X S}$ in eq. (7) calculating the summation of $\left[r_{h k l e x p}-r_{h k l c a l}\right]^{2}$ for 220,422 and 222 reflections are listed in Table 3 together with the values of $r_{h k l e x p}$ and $r_{\text {hklcal. }}$. For further convenience, the $f^{\prime}$ and $f$ "values used in this calculation are summarized in Table 4. It is also helpful to recall a few fundamental points of a spinel structure. In the so-called normal type spinel structure, all $\mathrm{M}$ cations prefer to occupy the tetrahedral A-site and $x=1.0$. On the other hand, the inverse type spinel structure where a tetrahedral position is not allocated to any $M$ cation correspond to the parameter $x=0.0$. As easily seen in the results of Table 3, the measured intensity ratio for the $\mathrm{ZnFe}_{2} \mathrm{O}_{4}$ case agrees well with that calculated for $x=1.0$. This quantitatively indicates that all of $\mathrm{Zn}^{2+}$ cations in $\mathrm{ZnFe}_{2} \mathrm{O}_{4}$ occupy only the tetrahedral positions (A-site). This result is also consistent with our previous study using synchrotron radiation ${ }^{11)}$. In $\mathrm{NiFe}_{2} \mathrm{O}_{4}$, the measured intensity ratio is reproduced only when using the $x$ value close to zero, so that all of $\mathrm{Ni}^{2+}$ cations are distributed at the
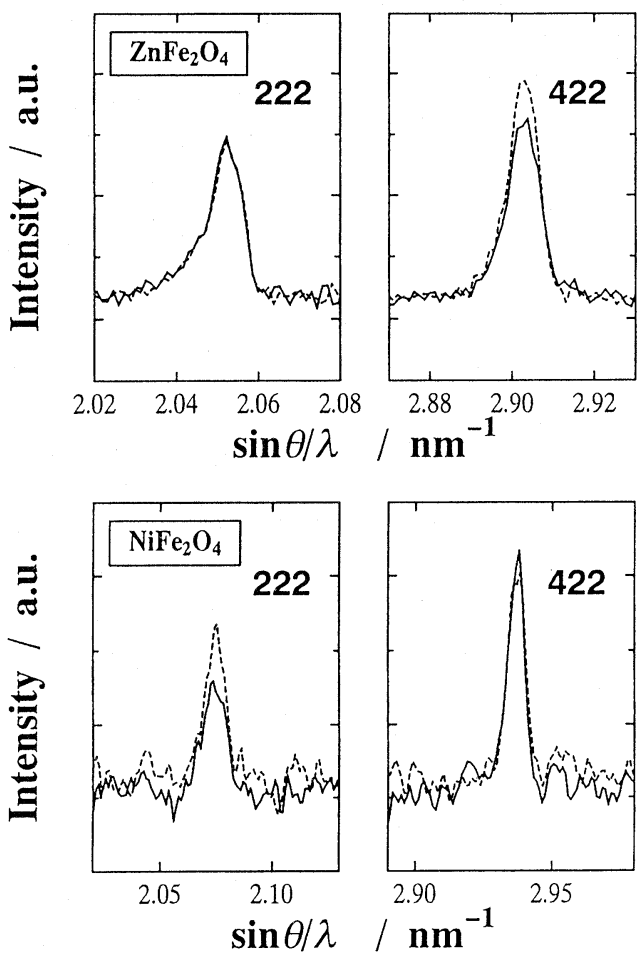

Fig. 4 The diffraction peak intensities of $\mathrm{ZnFe}_{2} \mathrm{O}_{4}$ and $\mathrm{NiFe}_{2} \mathrm{O}_{4}$ at two energies $E_{1}, E_{2}$ near the absorption edge $E_{\text {edge }}$ of $\mathrm{Zn}$ or Ni. Broken and solid lines are the intensity profiles at $\mathrm{E}_{1}$ and $\mathrm{E}_{2}$ respectively $\left(E_{\text {edge }}>E_{1}>E_{2}\right)$ 
Table 3 The values of $r_{\text {hblesp }}$ obtained from in-house AXS measurements, $r_{\text {hl, ol }}$ computed form models of cation distribution and the results of parameter $\mathrm{x}$ for $\mathrm{ZnFe}_{2} \mathrm{O}_{4}, \mathrm{NiFe}_{2} \mathrm{O}_{4}$ and $\mathrm{NiAl}_{2} \mathrm{O}_{4}$.

\begin{tabular}{|c|c|c|c|c|c|c|c|}
\hline \multirow[b]{2}{*}{ (reflection) } & & \multicolumn{2}{|c|}{$\mathrm{ZnFe}_{2} \mathrm{O}_{4}(\mathrm{Zn} K)$} & \multicolumn{2}{|c|}{$\mathrm{NiFe}_{2} \mathrm{O}_{4}(\mathrm{NiK})$} & \multicolumn{2}{|c|}{$\mathrm{NiAl}_{2} \mathrm{O}_{4}(\mathrm{NiK})$} \\
\hline & & $r_{\text {hlleepp }}$ & $r_{\text {hel, cal }}$ & $r_{\text {hldepp }}$ & $r_{\text {hl,col }}$ & $r_{\text {hlleep }}$ & $r_{\text {hld,al }}$ \\
\hline \multirow[t]{2}{*}{ tetrahedral } & 220 & 0.840 & 0.850 & 0.998 & 1.008 & 0.953 & 0.950 \\
\hline & 422 & 0.844 & 0.809 & 1.014 & 1.009 & 0.940 & 0.939 \\
\hline octahedral & 222 & 1.034 & 1.033 & 0.776 & 0.776 & 0.270 & 0.267 \\
\hline \multicolumn{2}{|c|}{$x=\mathrm{M}_{\mathrm{A}} / \mathrm{M}_{\text {total }}$} & \multicolumn{2}{|c|}{0.99} & \multicolumn{2}{|c|}{0.02} & \multicolumn{2}{|c|}{0.15} \\
\hline
\end{tabular}

octahedral positions (B-site).

These two results of $\mathrm{ZnFe}_{2} \mathrm{O}_{4}$ and $\mathrm{NiFe}_{2} \mathrm{O}_{4}$ quantitatively confirm that the in-house AXS measurements work well and its usefulness is considered as reliable as the case with synchrotron radiation ${ }^{11}$, with respect to the determination of cation distribution in the spinel type structure. In order to facilitate our understanding of this subject, the in-house AXS method has also been applied to $\mathrm{NiAl}_{2} \mathrm{O}_{4}$. The measurements and data processing were made along the way similar to the ferrite case. The results are given in the last column of Table 3 using numerical value of $x$. It is reasosnable to conclude that $15 \%$ of $\mathrm{Ni}^{2+}$ cations reside in the tetrahedral $\mathrm{A}$-site and the residual $\mathrm{Ni}^{2+}$ cations are considered to be octahedrally coordinated in $\mathrm{NiAl}_{2} \mathrm{O}_{4}$. It may also be stressed that this is the first quantitative information for the distribution of $\mathrm{Ni}^{2+}$ cations in $\mathrm{NiAl}_{2} \mathrm{O}_{4}$ obtained by applying the AXS method, although this conclusion is restricted to the synthetic condition employed in this work.

In conclusion, the usefulness of the in-house AXS method has been rather well-confirmed by obtaining the quantitative information of cation distrubution in three crystalline materials with a spinel type structure, although there are some inconvenient features of the intensity and the energy resolution and then the experimental uncertainty of $\pm 5 \%$ for the $x$ value should be cited in this work.

Table 4 The values of anomalous dispersion terms $f$ ' and $f$ " used in present work

\begin{tabular}{c|cccccc}
\hline Zn K edge & $f^{\prime}{ }_{\mathrm{Zn}}$ & $f^{\prime \prime}{ }_{\mathrm{Zn}}$ & $f_{\mathrm{Fe}}^{\prime}$ & $f^{\prime \prime}{ }_{\mathrm{Fe}}$ & $f^{\prime}$ & $f^{\prime \prime}{ }_{\mathrm{o}}$ \\
\hline $\mathrm{E}_{1}(9.636 \mathrm{keV})$ & -5.63 & 0.49 & -0.17 & 2.38 & 0.03 & 0.02 \\
$\mathrm{E}_{2}(9.525 \mathrm{keV})$ & -3.90 & 0.50 & -0.21 & 2.43 & 0.03 & 0.02 \\
\hline
\end{tabular}

\begin{tabular}{c|cccccccc}
\hline Ni K edge & $f^{\prime}{ }_{\mathrm{Ni}}$ & $f^{\prime \prime}{ }{ }_{\mathrm{Ni}}$ & $f^{\prime}{ }_{\mathrm{Fe}}$ & $f^{\prime \prime}{ }_{\mathrm{Fe}}$ & $f^{\prime}{ }_{\mathrm{Al}}$ & $f^{\prime \prime}{ }_{\mathrm{Al}}$ & $f^{\prime}{ }_{\mathrm{O}}$ & $f^{\prime \prime}{ }^{\circ}$ \\
\hline $\mathrm{E}_{1}(8.307 \mathrm{keV})$ & -5.54 & 0.48 & -0.91 & 3.05 & 0.20 & 0.23 & 0.04 & 0.03 \\
$\mathrm{E}_{2}(8.182 \mathrm{keV})$ & -3.38 & 0.49 & -1.03 & 3.13 & 0.20 & 0.24 & 0.05 & 0.03 \\
\hline
\end{tabular}




\section{Acknowledgement}

The authors thand Prof. H. Toraya, Nagoya, Institute of Technology, for providing the Rietveld program package.

\section{References}

1) H.St.C.O'Neill:Eur.J.Minerals, 4, 571 (1992)

2) M.E.Fleet:Acta. Crystallogr., B37, 917 (1981)

3) R.W.James:The Optical Principles of the Diffraction of X-rays, G.Bell \& Sons, London, (1954)

4) Y.Waseda:Novel Application of Anomalous X-ray Scattering for Structural Characterization of Disordered Materials, Springer-Verlag, Heidelberg, (1984)

5) D.T.Cromer and D.A.Liberman:J.Chem.Phys., 53, 1891 (1970)

6) International Tables for X-ray Crystallography, Vol.II, III and IV, D.Reidel Pub. Co.Ltd., Dordrecht, (1985)

7) B.D.Cullity: Elements of $X$-ray Diffraction (2nd Edition), Addison-Wasley Pub., Leading, (1978)

8) H.M.Rietveld; J.Appl.Crystallogr., 2, 65 (1969)

9) H.Toraya and F.Marumo: Rep. Res. Lab. Engin. Mater. Tokyo Institute of Technology, 5,55 (1980)

10) H.Toraya: J.Appl. Crystallogr., 19, 440 (1986)

11) K.Shinoda, K.Sugiyama, C.Raynales, Y.Waseda and K.T.Jacob; Shigen-to-Sozai, 111, 801 (1995). 